\title{
MICRONEEDLING VS. SCARS REMODELLING WITH 30\% SALICYLIC ACID- A COMPARATIVE STUDY
}

\author{
Garima Sharma1, Rakesh Jha²
}

${ }_{1}^{1}$ Assistant Professor, Department of Skin, Pt. J. N. M Medical College, Raipur, Chhattisgarh, India. ${ }^{2} 3^{\text {rd }}$ Year DNB, Department of Anaesthesia, Ramkrishna Care Hospital, Raipur, Chhattisgarh, India.

\section{BACKGROUND}

ABSTRACT

Acne scars are a cause of major psychological morbidity in the young population. Microneedling using dermarollers, which uses the principle of percutaneous collagen induction and scar remodelling using 30\% salicylic acid are both widely used methods for the treatment of acne scars and are cheaper alternatives to LASER resurfacing.

The aim of our study is to objectively compare the efficacy of microneedling using dermaroller and $30 \%$ salicylic acid in the management of acne scars.

\section{MATERIALS AND METHODS}

A non-randomised controlled trial study of 60 patients of acne scarring were taken and alternatively divided into Group A and B, out of which 28 patients offered multiple sittings of microneedling (1.5 mm dermaroller) under Group A and 32 patients with $30 \%$ salicylic acid peel under Group B. But 5 patients were lost for follow-up. Total of 4 sessions at monthly intervals were performed on both groups. Their scars were evaluated and graded clinically and by serial photography at the start as well as after the last session of treatment. The percentage improvement in the acne scar grade between the two groups was compared using the Fisher's test.

\section{RESULTS}

Among the 60 patients, 18 (72\%) patients in Group A (Microneedling) and 11 (36.66\%) patients in Group B (Salicylic Acid) noted significant reduction in their acne scar grade. The difference between the 2 groups was statistically significant with p-value of 0.0011 .

\section{CONCLUSION}

The techniques of microneedling and chemical peeling are both effective in acne scars. But Microneedling Therapy seems to be superior than $30 \%$ salicylic acid peeling for the management of acne scars in terms of effectiveness and side effects.

\section{KEY WORDS}

Acne Scars, Microneedling, Dermaroller, Percutaneous Collagen Induction, Scar Remodelling, Salicylic Acid.

HOW TO CITE THIS ARTICLE: Sharma G, Jha R. Microneedling vs. scars remodelling with 30\% salicylic acid- a comparative study. J. Evolution Med. Dent. Sci. 2018;7(37):4072-4076, DOI: 10.14260/jemds/2018/910

\section{BACKGROUND}

Acne is a chronic inflammatory disease of the pilosebaceous units characterised by the formation of comedones, erythematous papules and pustules, less frequently by nodules or pseudocysts. It is accompanied by scarring in some cases.[1] The psychological disadvantage of acne vulgaris extends even after its control, since post acne scarring is a permanent sequelae.[2] There are various procedures to treat acne scars such as lasers, microneedling and chemical peel. While lasers (Fractional CO2, Erb: YAG lasers) may be more effective, they are associated with a significant downtime. Affordability is a major limiting factor for the widespread use of lasers. In such scenarios, microneedling with dermarollers and chemical peeling using $30 \%$ salicylic acid are cost effective options. ${ }^{[3-4]}$

Aim- The aim of this study is to compare the efficacy of microneedling with dermarollers and chemical peeling using

'Financial or Other Competing Interest': None.

Submission 31-07-2018, Peer Review 25-08-2018,

Acceptance 31-08-2018, Published 10-09-2018.

Corresponding Author:

Dr. Garima Sharma

Department of Skin,

Pt. J. N. M Medical College,

Raipur-492001, Chhattisgarh, India.

E-mail: drsharmaji007@gmail.com

DOI: $10.14260 /$ jemds $/ 2018 / 910$
$30 \%$ Salicylic Acid in the management of acne scars. This study is also designed to study the adverse effect profile of both modalities of treatment.

\section{MATERIALS AND METHODS}

The non-randomised controlled trial study was carried out in the tertiary care hospital, where patients with various grades of acne scarring is attending the skin outpatient department. A total of 60 patients of acne scarring were taken. Sample size was taken for convenience.

Five patients did not come for follow-up. Therefore, only 55 patients completed the trial. The acne scars were graded according to Goodman and Baron grading (Table 1).[5] The patients were alternatively put into two groups- A and B. Group A received microneedling treatment and Group B received 30\% salicylic acid peeling. Each patient received 4 sessions at intervals of one month.

\begin{tabular}{|c|c|c|c|}
\hline Grade & $\begin{array}{c}\text { Level of } \\
\text { Disease }\end{array}$ & Clinical Feature & $\begin{array}{c}\text { Examples of } \\
\text { Acne Scar }\end{array}$ \\
\hline 1 & Macular & $\begin{array}{c}\text { Erythematous, hypo or } \\
\text { hyperpigmented flat marks } \\
\text { visible to patients and } \\
\text { observers irrespective of } \\
\text { distance }\end{array}$ & $\begin{array}{c}\text { Erythematous, } \\
\text { hypo or } \\
\text { hyper- } \\
\text { pigmented flat } \\
\text { marks }\end{array}$ \\
\hline 2 & Mild & $\begin{array}{c}\text { Mild atrophy or hypertrophy } \\
\text { that may be obvious at social } \\
\text { distance of 50 cm or greater } \\
\text { and maybe covered easily by } \\
\text { makeup. }\end{array}$ & $\begin{array}{c}\text { Mild rolling, } \\
\text { small soft } \\
\text { papular }\end{array}$ \\
\hline
\end{tabular}




\begin{tabular}{|c|c|c|c|}
\hline 3 & Moderate & $\begin{array}{c}\text { Moderate atrophic or } \\
\text { hypertrophic that may be } \\
\text { obvious at social distance of } \\
50 \mathrm{~cm} \text { or greater and not } \\
\text { covered easily by makeup, } \\
\text { but still able to be flattened } \\
\text { by manual stretching of skin. }\end{array}$ & $\begin{array}{c}\text { More } \\
\text { significant } \\
\text { rolling, } \\
\text { shallow } \\
\text { boxcar, mild- } \\
\text { to-moderate } \\
\text { hypertrophic } \\
\text { or papular } \\
\text { scars. }\end{array}$ \\
\hline 4 & Severe & $\begin{array}{c}\text { Severe atrophic or } \\
\text { hypertrophic that may be } \\
\text { obvious at social distance of } \\
50 \mathrm{~cm} \text { or greater and not } \\
\text { covered easily by makeup, } \\
\text { but not able to be flattened } \\
\text { by manual stretching of skin. }\end{array}$ & $\begin{array}{l}\text { Punched out } \\
\text { atrophic, ice- } \\
\text { pick, bridges } \\
\text { and tunnels, } \\
\text { marked } \\
\text { atrophy, } \\
\text { dystrophic } \\
\text { significant } \\
\text { hypertrophy } \\
\text { or keloid. }\end{array}$ \\
\hline & & 9 & ification $b$ \\
\hline
\end{tabular}

\section{Inclusion Criteria}

1. Acne scar patients of both sexes, aged b/w 15 - 45 years.

2. Patients having various Grades-II, III and IV acne.

3. Patients not responding to various topical or systemic modalities tried for acne scar for a minimum period of one year.

\section{Exclusion Criteria}

1. Patients with menstrual dysfunction.

2. Patients who had received other acne treatments within the previous 90 days

3. Pregnant or nursing women.

4. Patients on anti-tubercular drugs, $\beta$-blockers or contraceptive pills.

5. Those having other diseases requiring concomitant treatment.

\section{Technique of Microneedling (Dermaroller) Instrument}

Dermaroller with $1.5 \mathrm{~mm}$ needle length.

\section{Pre-Operative}

The area to be treated is properly cleansed. Prior to the treatment, topical anaesthetic is applied for one hour under occlusion which is then removed by acetone and the area sterilised by cleaning with povidone-iodine and spirit. Normal saline is used as a final cleanser to prevent any irritation.

A sterile rolling device with needles of length $1.5 \mathrm{~mm}$ is rolled across the skin with pressure in multiple directions until the area demonstrates uniform pinpoint bleeding through thousands of micropuncture sites. One study describes rolling the device four times in four different directions (horizontally, vertically and diagonally right and left) for a total of 16 passes.

\section{Post-Operative Care}

After the procedure, the area is cleansed with saline-soaked gauze and an occlusive ointment is applied. Generally, the skin oozes for less than 24 hours and then remains erythematous and oedematous for 2 to 3 days.

\section{Technique of Chemical Peeling}

\section{Equipment}

Salicylic acid 30\%, spirit, acetone, cold water, cotton buds, soap, towels, plastic sheets.

\section{1) Pre-peel}

a. Consent and explanation regarding the occurrence of a burning sensation of the skin during the procedure; peeling of the skin in ensuing days which should not be deliberately pulled off and the strict adherence to sun protection measures for 1 - 2 weeks.

2) Peel

a. Pour SA $30 \%$ in the glass beaker. Cotton bud is immersed in this solution and then apply with smooth strokes sequentially and unit wise- forehead, right cheek, chin, left cheek, glabella, nose, perioral area, upper and lower eyelids. Apply gently and upto/ into the borders and/or margins of eyebrows, hairline, vermilion border and submandibular region. This is called feathering.

b. Reaction: There is immediate whitening- salicylic acid frost, i.e. pseudo frost (within 30 seconds) due to crystallisation of salicylic acid on volatilisation of the vehicle on the skin surface. There is stinging and burning sensation over next 2 - 3 minutes, which decreases in 1 - 2 minutes (end point).

c. Wipe the frost with cold water or ask the patient to wipe it off after 5 - 10 mins.

\section{3) Post-Peel}

At home, cold water/ ice compresses and calamine lotion are given for drying and soothing. Apply emollients and keep the skin moist. Use of sunscreens is advised. Serial photographs were taken, one before the commencement of treatment and the repeated every month for all the patients. At the end of the fourth session, the percentage improvement in acne scars was noted. The observations were tabulated. The results were graded on the basis of the percentage improvement as follows-

Grade 0: Less than 25\% improvement.

Grade 1: 25 - 49\% improvement.

Grade 2: 50 - 74\% improvement.

Grade 3: More than 75\% improvement.

\section{Statistical Analysis}

Those patients with 1, 2 and 3 grades of improvement were taken to have improved. The percentage of those patients with improvement in Group A and Group B were compared using the Fisher test. The p-value was computed.

\section{RESULTS}

A total of 60 patients from the study group who were diagnosed as having acne scar were included in the study. Out of which 5 patients were lost for follow-up; hence, total 55 patients were present till the end of the study. These patients had no systemic disease.

Two groups of patients were formed with Group A consisting of 25 patients receiving Dermaroller, Group B of 30 patients receiving $30 \%$ salicylic acid peel. The response to the treatment was evaluated on the basis of the physician's clinical assessment, photographic evaluation at each sitting and patient's feedback after the fourth sitting, and at the 
three-month and the six-month follow-up period after the last treatment.

Side effects were observed. In salicylic acid peel, erythema and post-inflammatory hyperpigmentation were the major side effects. Using dermaroller erythema, hyperpigmentation and oedema were the major side effects.

Table 1. Response to Microneedling (Dermaroller) and Salicylic Acid Peeling (30\%)

Out of 25 patients treated with dermaroller, 12 showed excellent response, 06 showed good response and 07 showed poor response. Out of 30 patients treated with salicylic acid peeling (30\%) 03 showed excellent response, 05 showed good response and 22 showed poor response.

\begin{tabular}{|c|c|c|c|c|c|}
\hline & 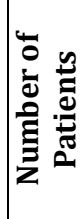 & 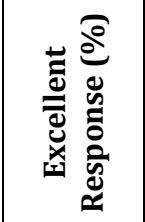 & 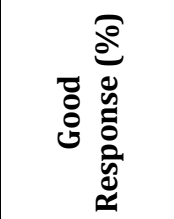 & 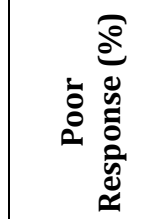 & $\begin{array}{l}\stackrel{0}{\Xi} \\
\frac{\pi}{2} \\
2\end{array}$ \\
\hline Microneedling & 25 & $12(48 \%)$ & $06(24 \%)$ & $07(28 \%)$ & 0.42 \\
\hline \begin{tabular}{|l} 
Salicylic Acid \\
Peeling (30\%)
\end{tabular} & 30 & $06(20 \%)$ & 05(16.66\%) & $19(63.33 \%)$ & 0.85 \\
\hline
\end{tabular}

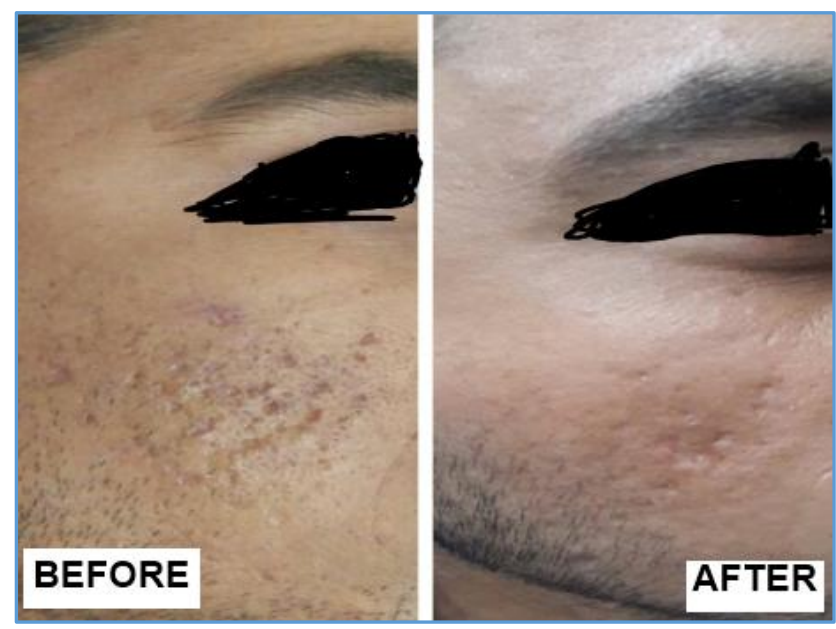

Figure 1. Microneedling

\begin{tabular}{|c|c|c|c|}
\hline & 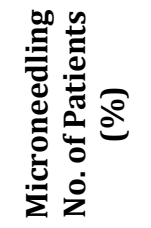 & 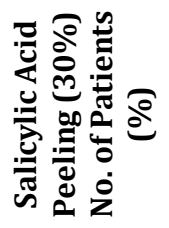 & $\begin{array}{l}\stackrel{0}{ٍ} \\
\stackrel{\pi}{2} \\
2\end{array}$ \\
\hline Hyperpigmentation & $05(20 \%)$ & $08(26 \%)$ & 0.023 \\
\hline Erythema & $03(12 \%)$ & $05(16 \%)$ & 0.001 \\
\hline Oedema & $07(28 \%)$ & $00(00)$ & 0.001 \\
\hline $\begin{array}{l}\text { Secondary } \\
\text { Infection }\end{array}$ & $00(00)$ & $00(00)$ & 0.00 \\
\hline \multicolumn{4}{|c|}{$\begin{array}{c}\text { Table 2. Complication of Dermaroller and Salicylic Acid } \\
\text { Peeling (30\%) }\end{array}$} \\
\hline
\end{tabular}

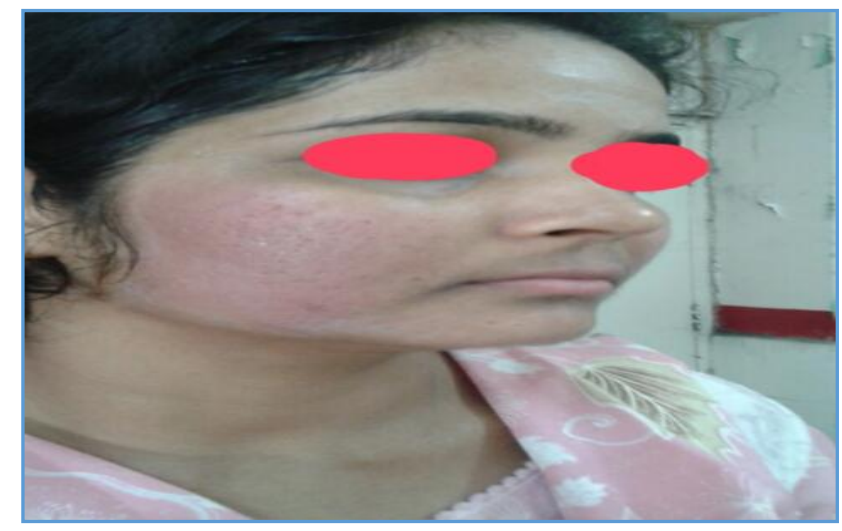

Figure 2. Complication of Microneedling

\section{Erythema and Oedema}

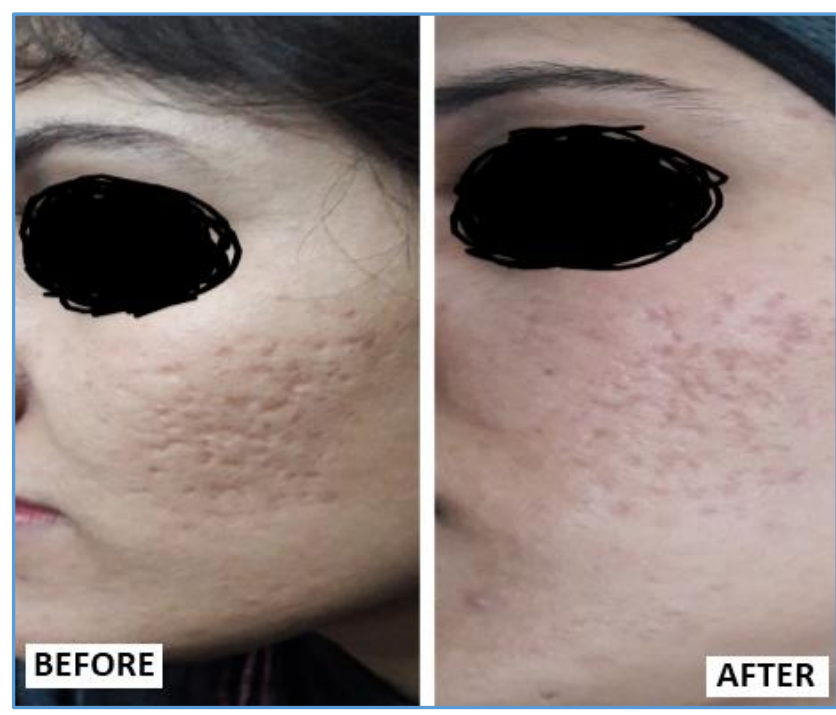

Figure 3. Result of Salicylic Acid Peeling

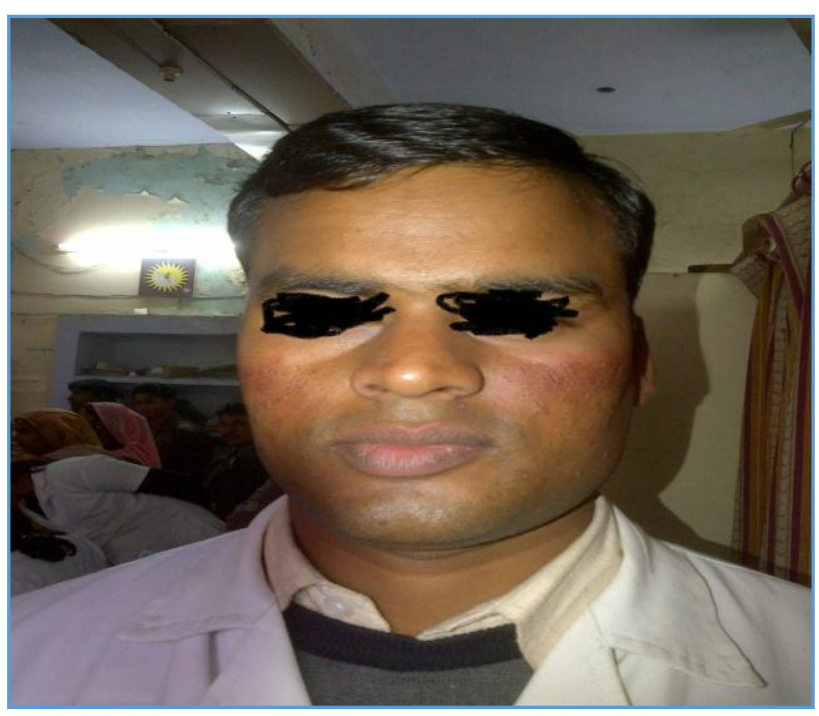

Figure 4. Post Peeling Erythema 


\begin{tabular}{|c|c|c|c|}
\hline $\begin{array}{c}\text { Total } \\
\text { Patients } \\
\text { 55 }\end{array}$ & $\begin{array}{c}\text { Number of } \\
\text { Patients } \\
(\mathbf{N = 5 5 )}\end{array}$ & $\begin{array}{c}\text { Good-to- } \\
\text { Excellent } \\
\text { Response }\end{array}$ & $\begin{array}{c}\text { Poor } \\
\text { Response }\end{array}$ \\
\hline Microneedling & 25 & $18(72 \%)$ & 07 \\
\hline Salicylic acid peel & 30 & $11(36.66 \%)$ & 19 \\
\hline \multicolumn{3}{|c|}{ Table 3. Comparative response of both modalities }
\end{tabular}

P-value: 0.0011 .

\section{RESULTS}

Among the 60 patients, $18(72 \%)$ patients in Group A (Microneedling) and 11 (36.66\%) patients in Group B (Salicylic Acid) noted significant reduction in their acne scar grade. The difference between the 2 groups was statistically significant with P-value: 0.0011 .

\section{DISCUSSION}

Scarring is a particularly distressing phenomenon and is most unwelcome when it occurs on the face. Scars can arise on the face due to a number of causes, the commonest of which is acne vulgaris. Post acne facial scarring is a psychologically devastating condition and has always been a challenge to treat.

Acne Scar is classified into: 1). Atrophic Scar (80\%) and 2) Hypertrophic Scar. Atrophic Scar is of 3 types-

a. Icepick (60-70\%).

b. Rolling (15 - 20\%).

b) Boxcar (20 - 30\%).

New acquisitions by the literature have showed that prevention is the main step in avoiding the appearance of post-acne scars.[6] The use of topical retinoids is useful in the prevention of acne scars.

In microneedling technique, the skin develops multiple microbruises in the dermis that initiate the complex cascade of growth factors that finally results in collagen production. Histology shows thickening of skin and a dramatic increase in new collagen and elastin fibres. Results generally start to be seen after about 6 weeks but the full effects can take at least three months to occur and as the deposition of new collagen takes place slowly the skin texture will continue to improve over a 12-month period. Microneedling can be safely performed on all skin colours and types: There is a lower risk of post-inflammatory hyperpigmentation than other procedures such as dermabrasion, chemical peelings and laser resurfacing.

Microneedling is contraindicated in the presence of anticoagulant therapies, active skin infections, collagen injections and other injectable fillers in the previous six months, personal or familiar history of hypertrophic and keloidal scars. ${ }^{[7,8]}$

There are many reports available which have studied the effects of each of these techniques individually. The percentage improvement seen in Group A, which underwent microneedling using dermaroller for 4 sessions which is $72 \%$ is comparable to that of the study done by Imran et al. The downtime observed for erythema and oedema to subside after the dermaroller procedure was 2 - 3 days, which was similar to that of the study by Fabroccini et al. The lesser downtime was also reported as an advantage in the study by Fernandes and Signorini et al, in which they reported that the absence of epidermal damage when compared to conventional acne scar treatments like dermabrasion as well as the newer treatments like Laser resurfacing.

Salicylic acid is one of the best peeling agents for the treatment of acne scars. ${ }^{[9]}$ It is a beta-hydroxy acid agent, which removes intercellular lipids that are covalently linked to the cornified envelope surrounding cornified epithelioid cells. The most efficacious concentration for acne scars is $20 \%$ to $30 \%$ in multiple sessions, 3 - 5 times, every $3-4$ weeks.[10,11,12] The side effects of salicylic acid peeling are mild and transient. These include erythema and dryness. Persistent post-inflammatory hyperpigmentation or scarring are very rare and for this reason it is used to treat dark skin.[13] Rapid breathing, tinnitus, hearing loss, dizziness, abdominal cramps and central nervous system symptoms characterise salicylism or salicylic acid toxicity.

\section{CONCLUSION}

The techniques of microneedling and $30 \%$ salicylic acid peeling are both effective in acne scars. When there is more of deep rolling and box scars, microneedling may be preferred. Chemical peeling using 30\% salicylic acid is more effective in superficial scars. Both techniques are cost effective; require less resources and safe modalities for management of acne scars. But microneedling scores in other aspects such as faster wound healing, better skin rejuvenation and safety in dark skinned individuals.

\section{REFERENCES}

[1] Kranning KK, Odland GF. Prevalence, morbidity and cost of dermatological diseases. J Invest Dermatol 1979;73(5 Pt 2):395-401.

[2] Koo J. The psychosocial impact of acne: patients' perceptions. J Am Acad Dermatol 1995;32(5 Pt 3):2630 .

[3] Kim HJ, Kim TG, Kwon YS, et al. Comparison of a 1, 550 nm Erbium: glass fractional laser and a chemical reconstruction of skin scars (CROSS) method in the treatment of acne scars: a simultaneous split-face trial. Lasers Surg Med 2009;41(8):545-9.

[4] Imran M. Microneedling therapy in atrophic facial scars: an objective assessment. J Cutan Aesthet Surg 2009;2(1):26-30.

[5] Satish D. Microneedling with dermaroller. J Cutan Aesthet Surg 2009;2(2):110-11.

[6] English RS, Shenefelt PD. Keloids and hypertrophic scars. Dermatologic Surgery 1999;25(8):631-8.

[7] Fernandes D. Minimally invasive percutaneous collagen induction. Oral and Maxillofacial Surgery Clinics of North America 2005;17(1):51-63.

[8] Fabbrocini G, Fardella N, Monfrecola A, et al. Acne scarring treatment using skin needling. Clinical and Experimental Dermatology 2009;34(8):874-9.

[9] Unna PG. Therapeutiques generales des maladies de la peau. 1882.

[10] Lazo ND, Meine JG, Downing DT. Lipids are covalently attached to rigid corneocyte protein envelopes existing predominantly as $\beta$-sheets: a solid-state nuclear magnetic resonance study. Journal of Investigative Dermatology 1995;105(2):296-300. 


\section{Jemds.com}

[11] Swinehart JM. Salicylic acid ointment peeling of the hands and forearms: effective nonsurgical removal of pigmented lesions and actinic damage. Journal of Dermatologic Surgery and Oncology 1992;18(6):4958.

[12] Imayama S, Ueda S, Isoda M. Histologic changes in the skin of hairless mice following peeling with salicylic acid. Archives of Dermatology 2000;136(11):1390-5.
Original Research Article

[13] Dinner MI, Artz JS. The art of the trichloroacetic acid chemical peel. Clinics in Plastic Surgery 1998;25(1):53-62. 